\title{
Antiserum to Rat Visceral Yolk Sac Endoderm Induced Abnormal Embryonic Development
}

\author{
CHRISTOPHER C. K. LEUNG ${ }^{(34)}$
}

Department of Anatomy, Louisiana State University School of Medicine, Shreveport, Louisiana, USA

\begin{abstract}
Summary
The induction of abnormal embryonic development by heterologous tissue antisera has been well established. The underlying mechanism whereby such teratogenesis occurs is not known. There were implications that visceral yolk sac endoderm might be involved. Endoderm was isolated from rat visceral yolk sac of 14th day of gestation using a nonenzymic procedure. The purity of the endoderm preparation was examined by electron microscopy. The preparation contained sheets of single layer of endodermal cells with no apparent contamination by the underlying mesenchyme or basal lamina. The specificity of the antiserum was examined by in vitro immunofluorescent localization studies. The antibodies against the endoderm localized only in the endodermal cells and some of the renal tubular cells. Intraperitoneal injection of the endoderm antiserum into 9-day pregnant rats resulted in congenital malformation, embryonic death, and fetal growth retardation. The effects of the antiserum were dose-dependent. The most frequently observed defects were anophthalmia and microphthalmia. Retarding effect of the antiserum on the growth of the embryo at the egg cylinder stage was also observed. In vivo immunofluorescent localization studies indicated that the endoderm antibodies localized only in the endodermal cells of the visceral yolk sac placenta; no localization was observed in the visceral yolk sac mesenchyme, basal lamina, Reichert's membrane, maternal kidney tissue or the embryo proper.
\end{abstract}

\section{Abbreviations}

FITC, fluorescein isothiocyanate

RM, Reichert's membrane

VYS, visceral yolk sac

The appearance of malformations in the offspring after intraperitoneal injection of rabbit antiserum directed against whole rat kidney homogenate into 9-day pregnant rats was first reported by Brent et al. (6). This finding has been repeatedly confirmed and extended by other investigators $(1,7,10,23,31)$. It was later demonstrated that the antiserum directed against rat chorioallantoic placenta (5) was also teratogenic and the placental antigens involved were glycoproteins (16). On the other hand, antisera to rat collagen (19), alpha-fetoprotein (22), renal glomerular basement membrane (21), whole serum, erythrocyte, spleen, brain, muscle and skin (6) seemed to have little effect on embryonic development when they were similarly injected into pregnant rats during the organogenetic period. Although the mechanism whereby teratogenic antisera induce abnormal embryonic development is not understood, immunofluorescent studies demonstrated that the antibodies of teratogenic antisera localized in vivo in the cytoplasm of the visceral yolk sac (VYS) endodermal cells as well as in the maternal glomeruli $(29,21)$. The absorption studies reported by Jensen et al. (13) utilizing antiserum against whole term VYS suggested that the localization of antibodies in the VYS endodermal cells might contribute to the cause of ab- normal embryonic development. It seemed logical to determine whether antigens of the VYS endodermal cells were indeed capable of stimulating teratogenic antibody production. This communication reports the isolation of pure VYS endodermal cells using the nonenzymic procedure described by Dziadek (8); rabbit antiserum directed against the pure VYS endodermal cells was a potent teratogenic agent when administered into 9-day pregnant rats.

\section{MATERIALS AND METHODS}

Timing of pregnancy. Random-bred Wistar rats were mated for $14 \mathrm{~h}$ overnight. Females that had been inseminated were considered to be $0 \mathrm{~h}, 0$ day pregnant at $9 \mathrm{AM}$ the next morning or at the beginning of the Ist day of pregnancy. Rats were housed in stainless steel cages and given food (Purina Mouse Chow) and water ad libitum.

Isolation of visceral yolk sac endoderm. Pregnant rats of 14th day of gestation were killed by overdose sodium pentobarbital. VYS were carefully dissected under a dissecting microscope from the conceptuses using watchmaker's forceps, and incubated in a solution of $1 \mathrm{M}$ glycine maintained at $37^{\circ} \mathrm{C}$ in a water-bath for 40-60 min according to the method described by Dziadek (8). Sheets of the endodermal layer were peeled away from the underlying mesodermal layer, pooled and lyophilized.

Electron microscopy. The separated endoderm and mesoderm were fixed in $3 \%$ glutaraldehyde in $0.1 \mathrm{M}$ phosphate buffer, $\mathrm{pH}$ 7.4 , and $1 \%$ osmium tetroxide in Sorenson's buffer, dehydrated through propylene oxide and embedded in Maraglas 655. Ultrathin sections, stained with uranyl acetate and lead citrate, were examined with a RCA M4 electron microscope.

Production of antisera. New Zealand white female rabbits weighing about $2.5 \mathrm{~kg}$ each were utilized for the production of antiserum by the method previously reported (18). One $\mathrm{mg}$ of lyophilized VYS endoderm was mixed with $3 \mathrm{ml}$ of phosphate-buffered saline, pH 7.3. The mixture was emulsified with equal volume of complete Freund's adjuvant (Difco). One-half $\mathrm{ml}$ of the emulsion was used for each immunization. Two rabbits were utilized and both were initially immunized once in the footpads. Subsequent subcutaneous multiple-site injections were given weekly for $5 \mathrm{wk}$. Rabbits were bled weekly from the central artery of the ear after the fourth injection. One week after the last injection, the rabbits were anesthetized with ether and exsanguinated by cardiac puncture. Sera from multiple bleedings were pooled, decomplemented at $56^{\circ} \mathrm{C}$ for $30 \mathrm{~min}$, and stored at $-20^{\circ} \mathrm{C}$. Antibody titers of the antisera were determined by serial dilutions and immunoprecipitation was observed by double immunodiffusion in agar gel using $1 \mathrm{mg}$ of VYS endoderm per $\mathrm{ml}$ saline as the antigenic mixture. Control serum was obtained from the rabbits before immunization.

Evaluation of antiserum of embryonic development. The biologic effects of the antiserum on embryonic development were examined in the following manner. On the 9th day of gestation, pregnant rats were injected intraperitoneally with various dosage of pooled 
antiserum. Control pregnant rats were injected similarly with preimmunization rabbit serum. All rats were anesthetized with sodium pentobarbital $(30 \mathrm{mg} / \mathrm{kg})$ before intraperitoneal injection. The mothers' weights were not recorded after exposure to the antiserum. The mothers were killed on the 22nd day of gestation and fetuses were delivered by caesarean section. The fetuses were examined grossly, weighed, and fixed in Bouin's fixative for dissection. The incidence of malformations was determined by the cross-sectional technique described by Wilson (32). Three 9-day pregnant rats were injected with $0.4 \mathrm{ml}$ of antiserum/100 $\mathrm{g}$ of animal weight. They were killed $24 \mathrm{~h}$ later. Egg cylinders were subsequently dissected from the uteri under a dissecting microscopy and measurements were taken of individual length of the egg cylinders. Egg cylinders were likewise obtained from pregnant rats injected with preimmunization rabbit serum and measurements were taken.

Immunofluorescent localization studies. After the intraperitoneal injection of the antiserum into pregnant rats on the 9 th day of pregnancy, the mothers were killed 24 or $48 \mathrm{~h}$ later. Maternal kidneys and embryonic tissues were examined for the in vivo localization of the injected antibodies with the indirect fluorescent antibody technique as described previously (19). FITC-conjugated goat anti-rabbit immunoglobulins was purchased from Calbiochem-Behring Corp. Absorption of the FITC-goat antibodies was performed twice by using $100 \mathrm{mg}$ of lyophilized Wistar rat liver powder per $\mathrm{ml}$ of reconstituted FITC-goat antibodies for 1 $\mathrm{h}$ at room temperature. The absorbed FITC-goat antibodies were diluted 20 -fold before use for staining. In vitro localization of antibodies in the rabbit antiserum directed against VYS endoderm was also performed on 4-micron sections of VYS and kidney tissues obtained from untreated rats. The rabbit antiserum was twice absorbed with lyophilized rat liver powder and diluted 20fold before use for staining the tissue sections. Examination of the stained sections were made using a Leitz fluorescent microscope with an XBO ultraviolet lamp. Photographs were taken with Kodak Tri-X (ASA 400) film.

\section{RESULTS}

Biologic effects of antiserum. The results of testing for biologic effects of the antiserum against VYS endoderm on embryonic development are summarized in Table 1 . The pooled antiserum was found to be a very potent embryopathic agent. It induced congenital malformations, fetal growth retardation and embryonic deaths which were observed at term as resorption sites. Injection of $0.2 \mathrm{ml}$ of antiserum/ $100 \mathrm{~g}$ of pregnant rat induced abnormalities in $92.7 \%$ of the surviving fetuses. Administration of $0.6 \mathrm{ml} / 100 \mathrm{~g}$ of pregnant rat killed $94 \%$ of the implanted embryos. The effects of the antiserum were dose-dependent. The spectrum of malformations was similar to that reported by Brent (4) using antiserum against whole rat kidney homogenate. The most frequently observed congenital defects were anophthalmia and microphthalmia. Other gross abnormalities such as hydrocephaly, omphalocele, anencephaly and club feet were also observed. Some of the mothers injected with lower dosage of antiserum were allowed to deliver their abnormal offspring. Many of those with no abnormalities except eye defects survived and grew up to be adults of normal size and weight (Fig. 1). The effect of the antiserum on the growth of the embryos at the egg cylinder stage was striking: $24 \mathrm{~h}$ after the administration of the antiserum the mean size of the egg cylinders was significantly different from that of the controls. The mean fetal weights at term of treated animals were also significantly different from that of the controls.

In vivo localization of antibodies. Specific immunofluorescent localization of teratogenic antibodies was observed in VYS endodermal cells (Fig. 2) of 10th day gestational age, that is, $24 \mathrm{~h}$ after the administration of the antiserum. Similar staining was also observed in the endodermal cells $48 \mathrm{~h}$ after the administration of the teratogenic antiserum. Neither the embryo itself nor Reichert's membrane (the basal lamina of the parietal yolk sac) was stained. Furthermore, there was no antibody localization in the maternal kidney tissue.

In vitro localization of antibodies. Specific immunofluorescent staining was observed in the VYS endoderm (Fig. 3) of all gestational ages examined (9-20th day). There was no staining in the VYS basal lamina, VYS mesenchyme, mesothelial cells lining the exocoelom, blood vessels, Reichert's membrane, parietal yolk sac cells or trophoblast cells. Specific fluorescent staining was observed in some renal tubular cells: but it appeared that there was no staining in the loop of Henle or distal convoluted tubules (Fig. 4). There was no staining in the renal glomeruli, blood vessels or other renal tissues. Furthermore there was no staining in the VYS from which the endoderm had been removed by the $1 \mathrm{M}$ glycine method.

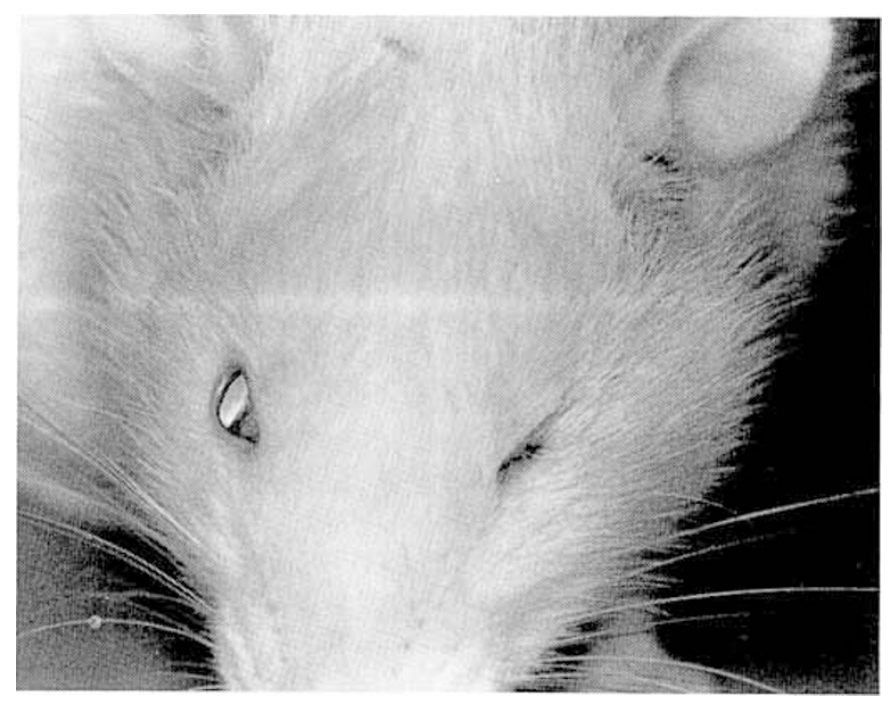

Fig. 1. An adult rat whose mother was injected with rabbit antiserum directed against rat visceral yolk sac endoderm on the 9th day of pregnancy. This rat has an abnormal right eye and his left eye is absent.

Table 1. Effect of antisera against visceral yolk sac endoderm on embryonic development

\begin{tabular}{|c|c|c|c|c|c|c|c|c|}
\hline Rabbit serum & $\begin{array}{c}\begin{array}{c}\text { Number of } \\
\text { litters }\end{array} \\
\end{array}$ & $\begin{array}{c}\mathrm{ml} \text { antiserum/ } \\
100 \mathrm{~g} \text { pregnant } \\
\text { rat }\end{array}$ & $\begin{array}{c}\text { Embryonic re- } \\
\text { sorption (\%) }\end{array}$ & \multicolumn{2}{|c|}{ Surviving Fetuses } & $\begin{array}{l}\text { Fetal weight at term } \\
(\mathrm{g}) \text { mean } \pm \text { S.D. }\end{array}$ & \multicolumn{2}{|c|}{ Egg cylinders } \\
\hline \multirow[t]{2}{*}{ Sac endoderm } & 5 & 0.2 & 20 & 41 & 92.7 & $4.05 \pm 0.62$ & & \\
\hline & 5 & 0.6 & 94 & 3 & 100 & $3.14 \pm 0.43$ & & \\
\hline Preimmunization & 9 & 0.5 & 11 & & 1.2 & $4.68 \pm 0.57$ & & \\
\hline Serum & 2 & 0.4 & & & & & 21 & $1.85 \pm 0.21$ \\
\hline
\end{tabular}


Electron microscopy. Electron microscopic examination of the sheets of VYS endoderm revealed that they were of single layer of epithelial cells free of the underlying basal lamina. Most of the endodermal cells appeared to have suffered from hypotonic shock due to the treatment with $1 \mathrm{M}$ glycine solution. Most of the cells had abnormal ultrastructures: some had disrupted plasma membrane, swollen mitochondria, and numerous empty vacuoles (Fig. 5). Examination of the VYS tissue from which the endoderm had already been removed showed that the basal lamina remained attached to the mesenchyme (Fig. 6).

\section{DISCUSSION}

Dziadek (8) first described the technique utilizing a hypotonic solution of $1 \mathrm{M}$ glycine to separate rodent visceral yolk sac endoderm from mesoderm without using enzymes such as trypsin or collagenase. Our present investigation confirmed her findings; sheets of endoderm could be removed after $1 \mathrm{M}$ glycine treatment. The advantage of using a chemical method over enzymatic treat-

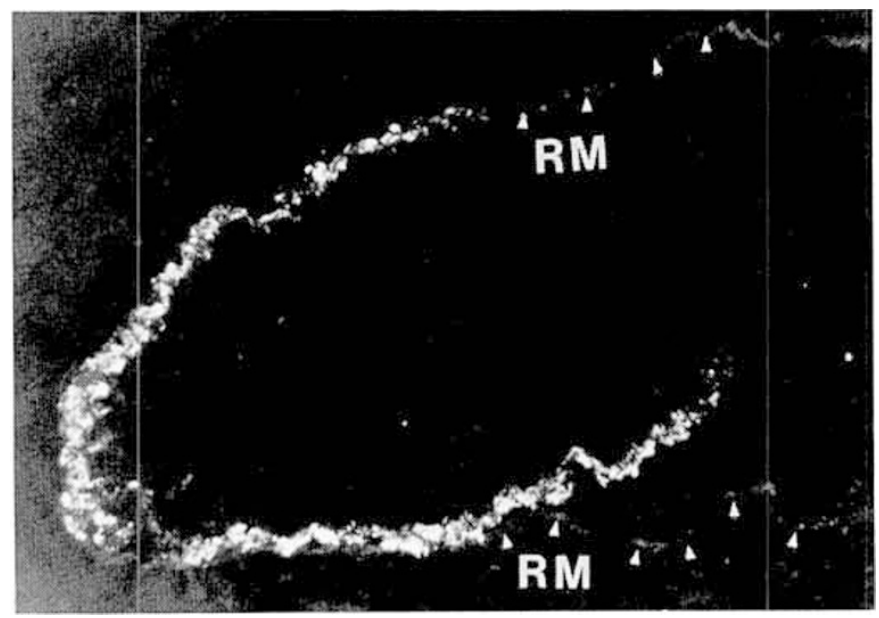

Fig. 2. In vivo immunofluorescent localization of rabbit teratogenic visceral yolk sac endoderm antibodies in the visceral yolk sac endodermal cells. Tissue was examined $24 \mathrm{~h}$ after injection of the antibodies into a 9day pregnant rat. Reichert's membrane $(R M)$ was not stained, $\times 250$. ments for our work is obvious when antigenic considerations are important. Our present investigation further extended Dziadek's work by electron microscopic examination of the endoderm preparation. Although the ultrastructures appeared to be abnormal, the endoderm cells thus isolated were essentially free of contamination by the underlying basal lamina or other mesenchymal tissue. Our in vitro immunofluorescent studies also agreed with the electron microscopic observations because there was no staining of the visceral basal lamina or Reichert's membrane. Previously studies, which utilized teratogenic antiserum against whole yolk sac, showed that both of these structures were stained (13); thus, we obtained an antiserum directed against antigenic components derived primarily from VYS endodermal cells.

This investigation clearly demonstrated for the first time that rabbit antiserum directed against rat VYS endoderm caused abnormal embryonic development. It also demonstrated the immediate growth retarding effect of the embryotoxic antiserum on rat embryos exposed in vivo to the antiserum at the egg cylinder stage. This finding lends support to the observation reported by New and Brent (24) relative to the growth retarding effect of antiserum directed against whole yolk sac on embryos grown in culture.

The mechanism of action of teratogenic antisera directed against various tissue preparations such as rat kidney homogenate, chorioallantoic placenta, or whole visceral yolk sac, is not understood. Three hypotheses have been proposed (4): (1) a direct effect of antibodies on the embryo proper; (2) secondary effect due to immunologic disease of the mother; and (3) yolk sac placental dysfunction.

Although numerous immunofluorescent studies in our laboratory and others indicated that there was no teratogenic antibody localization in vivo in the embryo proper, the question whether heterologous antibodies ever reached the embryo during the period of organogenesis is of obvious importance. It is known that homologous antibodies are transmitted from the mother to the fetus in the last third of pregnancy (see Brambell (3) for review). It is also well established that heterologous IgG can be transported across the maternofetal barrier in the direction of mother to the fetus in rodents and rabbits $(12,15,28)$. Heterologous $\operatorname{IgG}$ are known to be transmitted similarly as homologous IgG, although the rates of transmission may be different; however, all of these previous studies were performed at later stage of gestation, that is, beyond the period of organogenesis. The presence of maternal immunoglobulins in the mouse embryo proper examined from the

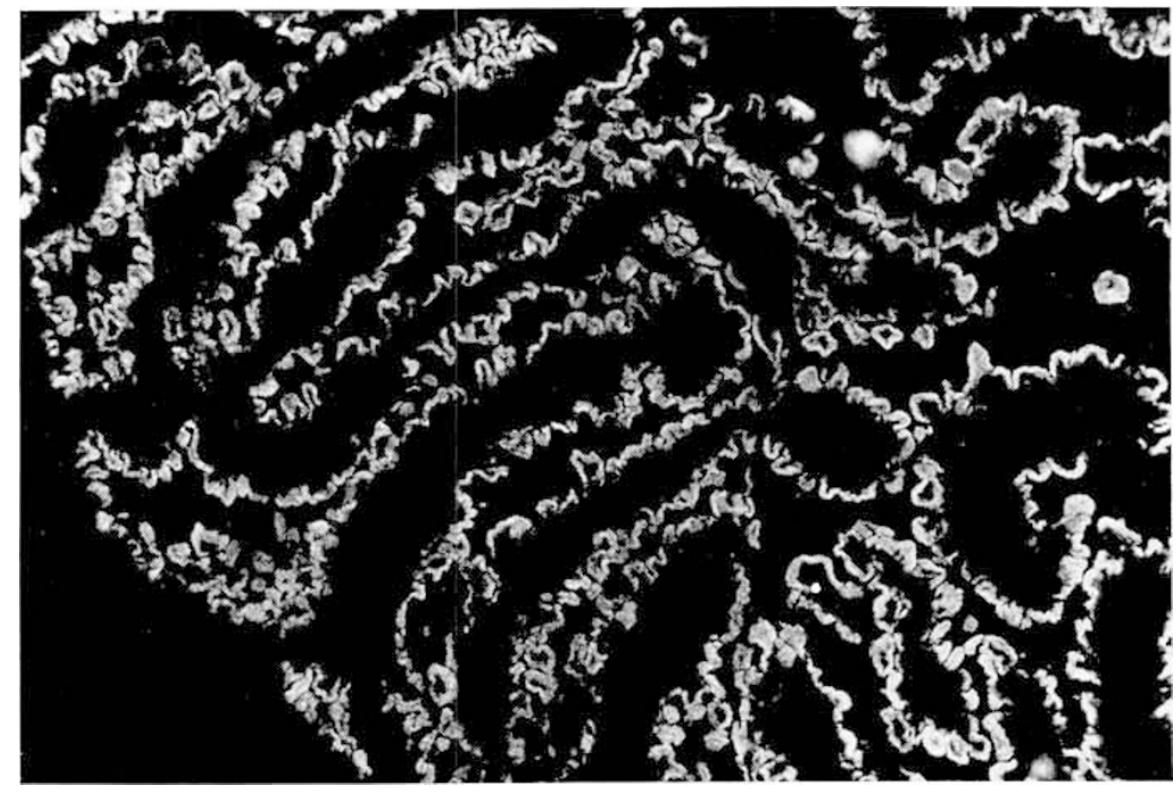

Fig. 3. In vitro immunofluorescent localization of rabbit teratogenic visceral yolk sac endoderm antibodies in the visceral yolk sac endoderm cells on the 20 th day of gestation. Similar staining was observed in the visceral yolk sac endodermal cells of earlier gestation. Neither the visceral basal lamina, mesenchyme, blood vessels, nor the mesothelium was stained, $\times 140$. 


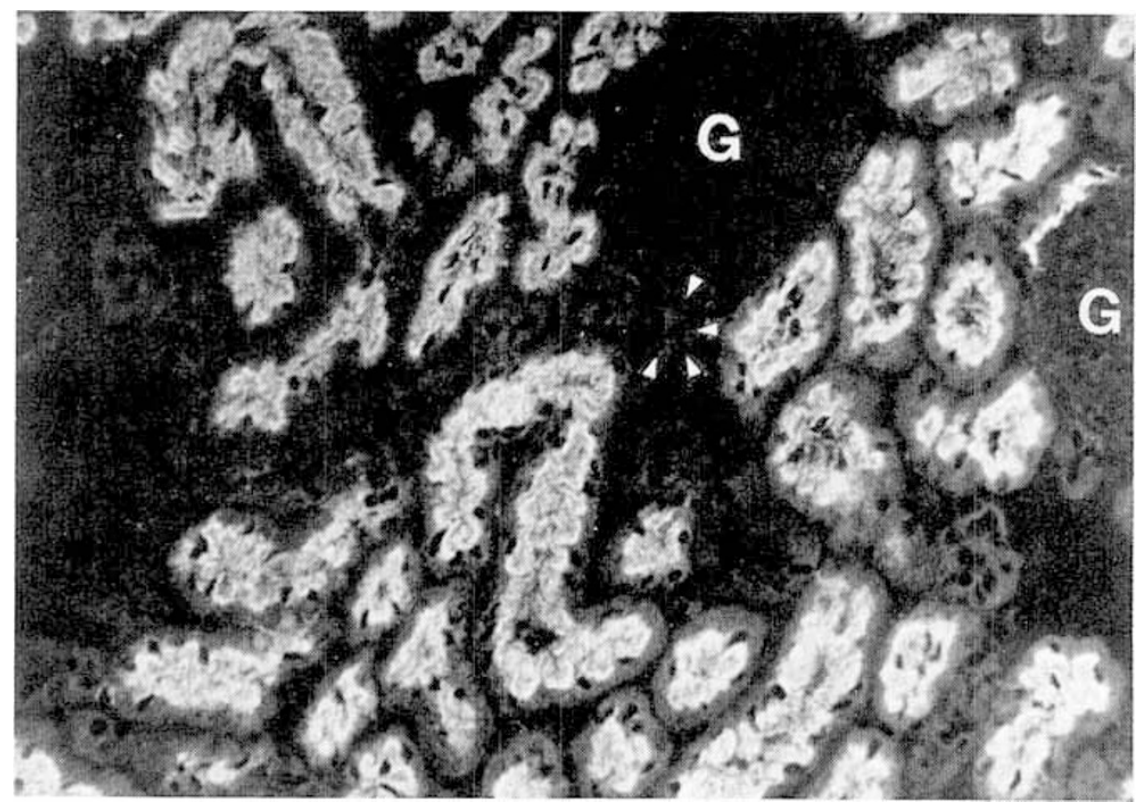

Fig. 4. In vitro immunofluorescent localization of rabbit teratogenic visceral yolk sac endoderm antibodies in some renal tubular cells. Fluorescent staining was absent in the glomeruli $(G)$, loop of Henle (arrows) and distal convoluted tubular cells, $\times 160$.

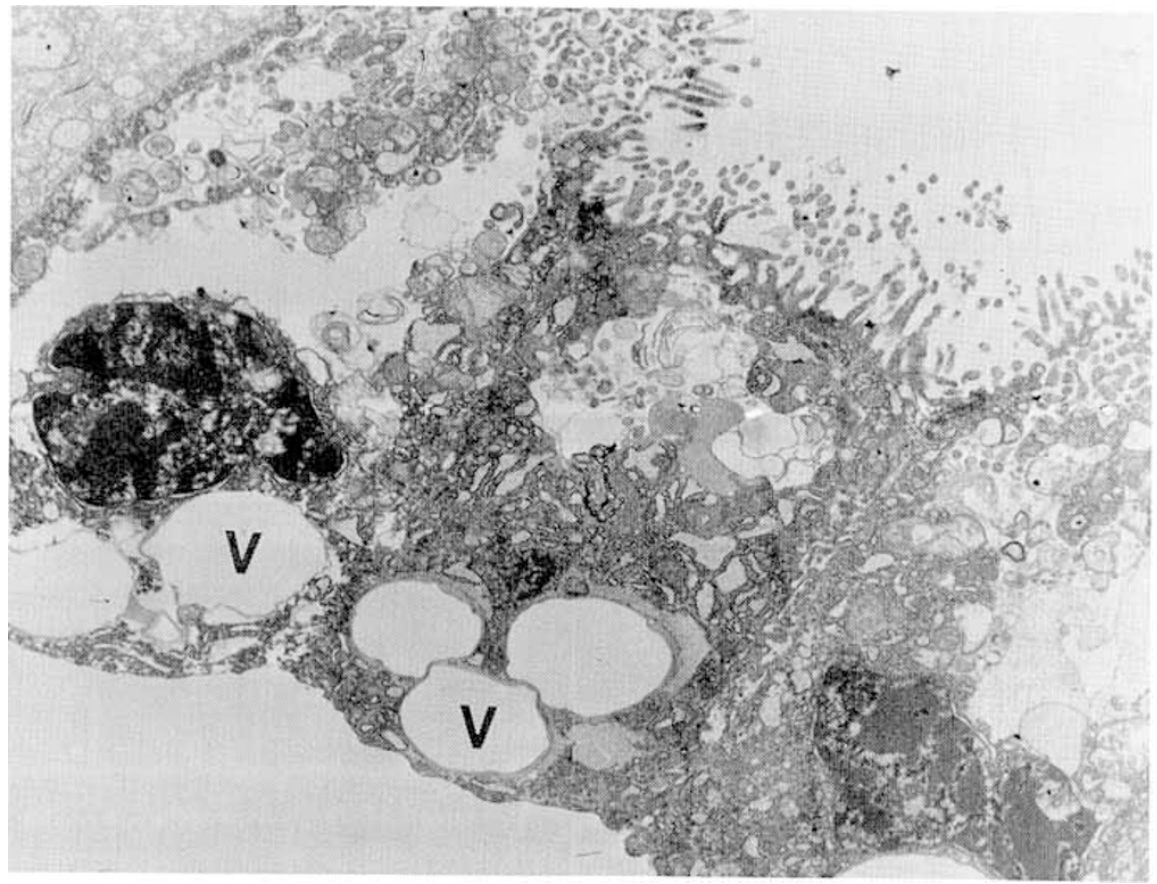

Fig. 5. An electron micrograph of the visceral yolk sac endodermal cells isolated with I M glycine. Many large vacuoles $(V)$ are present on the basal side of the cells. Note the absence of the basal lamina, $\times 6600$.

6-11th day of gestation (including the organogenetic period) was demonstrated by an immunoperoxidase method (2). Because heterologous antibodies are known to be similarly transmitted as homologous antibodies from the mother to the fetus at a later stage of gestation and because homologous maternal antibodies are present during the organogenetic period in the mouse embryo, it is difficult to perceive that heterologous antibodies would be selectively excluded from reaching the embryo during the organogenetic period. It is, therefore, difficult to disregard the first hypothesis in spite of the fact that our present investigation did not find localization of teratogenic antibodies in the embryo proper. It is possible that a small amount of teratogenic antibodies might have escaped detection by the immunofluorescent tech- nique. Such a possibility must be further examined by a more sensitive immunoperoxidase technique.

The second hypothesis assumes that birth defects are the results of maternal immunologic disease. For example, heterologous antiserum directed against rat kidney homogenate is known to be nephrotoxic (30) and would induce "Masugi" nephritis, which resembles the pathology of human glomerulonephritis. Strong evidence has been presented (21) to support the view that teratogenicity and nephrotoxicity of kidney antisera are of separate biologic properties. The nephrotoxicity of the antisera did not parallel their teratogenicity (21). The result of our present investigation on the in vivo immunofluorescent localization of teratogenic endoderm antibodies indicated that the antibodies did not 


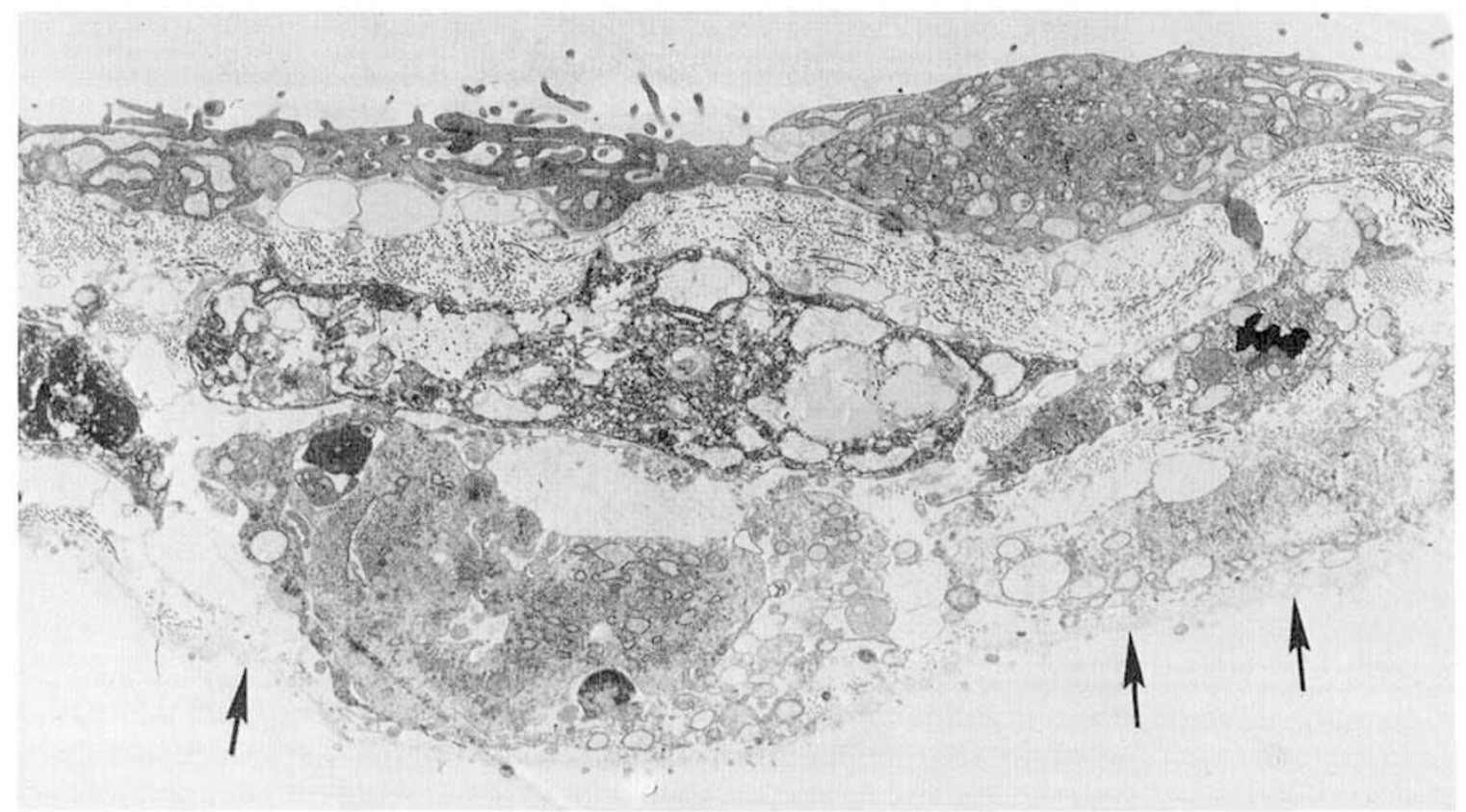

Fig. 6. An electron micrograph of the visceral yolk sac from which the endoderm has been removed. The basal lamina indicated by the arrows is still attached to the mesenchyme, $\times 9600$.

localize in the maternal kidneys. This finding adds support to the contention that birth defect induced by tissue antibodies may not result from maternal kidney immunologic disease.

The third hypothesis considers the possible dysfunction of yolk sac placenta caused by tissue antibodies. The rodent yolk sac placenta consists of parietal and visceral yolk sacs. In their earlier investigation (19), Leung and his colleagues observed that the heterologous antisera directed against several extracts of visceral yolk sac membrane preparations were teratogenic. Later, Jensen et al. (13) reported that Reichert's membrane antiserum induced abnormalities in less than $8 \%$ of the surviving fetuses when a $L_{50}$ dose of antiserum was used, whereas Leung (17) observed a much higher incidence of congenital defects using the same antiserum. There is no doubt that Reichert's membrane antiserum can induce birth defect. It seemed that Reichert's membrane antiserum was not as potent a teratogen as antiserum against whole visceral yolk sac (13). The results of our present investigation suggests that VYS endoderm alone contains high concentration of the responsible antigens. It required less than half of a mg of endoderm to produce a potent teratogenic antiserum in the rabbit. The result of our present in vivo immunofluorescent studies demonstrated the endoderm antiserum localized only in the endodermal cells. The distinction between two possible sites for teratogenesis in the yolk sac placenta is interesting. The fixation of antibodies on Reichert's membrane alone may alter the selective permeability of the latter because it has been suggested that it may play a role in regulating maternal-fetal interchange in early gestation (14). On the other hand, the fixation of antibodies on the VYS endodermal cells may interfere with normal transport or histiotrophic function of the VYS epithelium since the rat VYS has been regarded as an organ for active transport of nutrient to the embryo as well as respiratory exchange between the mother and the conceptus, especially before the establishment of the chorioallantoic placenta.

The nature of the antigen in the VYS endoderm which stimulates the production of teratogenic antibodies is not known. It is known that there are common antigens among kidney, yolk sac and chorioallantoic placenta $(25,26,27,29)$. It is conceivable that there may be more than one antigens which are responsible for the production of teratogenic antibodies. Partial purification of the responsible kidney antigens from two different sources has been reported $(18,20)$. The responsible kidney antigens were identified as glycoproteins of large molecular weights. In vitro immunofluorescent localization studies of teratogenic antibodies directed against the more purified fractions of kidney tissue indicated that the antigenic source was primarily from the renal tubular cells (unpublished results). The result of our present in vitro immunofluorescent localization studies on antiserum against the VYS endoderm demonstrated that the antigens in the VYS endoderm crossreacted with that of some renal tubular cells, presumably the proximal convoluted tubular cells. The fact that the teratogenic effect of the VYS endoderm antiserum could be completely removed after the antiserum was absorbed with $70 \mathrm{mg}$ of rat kidney powder per $\mathrm{ml}$ of antiserum for half an hour at room temperature (data not shown) also supports the notion that the responsible endoderm antigens are present in the kidney.

The exact molecular mechanism whereby teratogenic antibodies induces birth defects is still not clear. Recently Freeman and his colleagues (9) reported that the teratogenic antiserum directed against whole visceral yolk sac greatly decreased the pinocytotic uptake of proteins by embryos grown in culture. These authors suggested that interference with the availability of amino acids to the developing embryo might result in teratogenesis.

\section{REFERENCES AND NOTES}

1. Barrow, M. V. and Taylor, W. J.: The production of congenital defects in rats using antisera. J. Exp. Zool., 176: 41 (1971).

2. Bernard, O., Ripoche, M.-A., and Bennett, D.: Distribution of maternal immunoglobulins in the mouse uterus and embryo in the days after implantation. $J$. Exp. Med., 145: 58 (1977).

3. Brambell, F. W. R.: The transmission of passive immunity from mother to young. In "Frontiers of Biology" Vol. 18. (North-Holland, Amsterdam, 1970).

4. Brent, R. L.: The production of congenital malformations using tissue antisera II. The spectrum and incidence of malformations following the administration of kidney antiserum to pregnant rat. Am. J. Anat., 115: 525 (1964).

5. Brent, R. L.: Production of congenital malformations using tissue antisera. III Placental antiserum. Proc. Soc. Exp. Biol. Med., 125: 1024 (1967).

6. Brent, R. L., Averich, E., and Drapiewski, V. A.: Production of congential malformations using tissue antibodies. I. Kidney antisera. Pro. Soc. Exp. Biol. Med., 106: 523 (1961).

7. David, G., Mercier-Parot, L., and Tuchmann-Duplessis, H.: Action teratogene d'hetero-anticorps tissularies. I. Production de malformations chez le rat par action dun serum anti-rein. C. R. Seances Soc. Biol., 157: 939 (1963).

8. Dziadek, M. A.: Use of glycine as a non-enzymic procedure for separation of mouse embryonic tissue and dissociation of cells. Exp. Cell Res., 133: 383 (1981).

9. Freeman, S. J., Lloyd, J. B., Jensen, M., Koszalka, T. R., and Brent, R. L.: The production of congenital malformations in the rat using tissue antisera. XVI. 
The effect of teratogenic antiserum on yolk sac function in rat embryos cultured in vitro. Teratology, 25: 42A (Abstract) (1982).

10. Gebhardt, D. O., Baart de la Faille-Kuyp, and Nagel, J.: The embryolethality and localization of antikidney serum in the pregnant mouse, Mus musculus. Teratology, 3: 145 (1970).

11. Gitlin, D. and Morphis, L. G.: System of materno-foetal transport of G immunoglobulin in the mouse. Nature, 223: 195 (1969).

12. Hemmings, W. A., Jones, R. E., and Faulk, W. P.: Transport across the rabbit foetal yolk-sac of fractions of $\mathrm{IgG}$ from several mammalian species. Immunology, 28: 4II (1975).

13. Jensen, M. A., Koszalka, T. R., and Brent, R. L.: Production of congenital malformations using tissue antisera. XV. Reichert's membrane and visceral yolk sac antisera. Dev. Biol., 42: 1 (1975).

14. Jollie, W. O.: Changes in the fine structure of the parietal yolk sac of the rat placenta with increasing gestational age. Am. J. Anat., 122: 513 (1968).

15. Koch, D., Boesman, M., and Gitlin, D.: Maternofoetal transfer of gamma G immunoglobulins. Nature, 216: 1116 (1967).

16. Leung, C. C. K.: Congenital malformations induced by rabbit antiserum against rat placental glycoproteins isolated by Con A affinity chromatography. Teratogenic antibodies are not nephrotoxic. Pediatr. Res., 16: 973 (1982).

17. Leung, C. C. K.: Embryotoxic effects of heterologous antisera against rat Reichert's membrane. J. Exp. Zool., 200: 295 (1977).

18. Leung, C. C. K. and Brent, R. L.: Partial purification and characterization of trypsin-solubilized rat kidney antigens that stimulate the production of teratogenic antibodies. J. Immunol., 124: 1267 (1980).

19. Leung, C. C. K., Brent, R. L., and Koszalka, T. R.: The production of congenital malformation using tissue antisera. XI. Antisera to acellular visceral yolk sac. Teratology, 6: 317 (1972).

20. Leung, C. C. K., Hung, C. H., Hudson, B. G., Brent, R. L., and Cotton, R. C. Congenital abnormalities induced by heterologous antisera directed against rat kidney glycoproteins isolated by concanavalin A affinity chromatography. Pediatr. Res., 13: 1211 (1979).

21. Leung, C. C. K., Urdaneta, A., Jensh, R. P., Hensen, M., and Brent, R. L.: Evidence that different antibodies are involved in the production of immunologically induced teratogenesis and nephritis. J. Immunol., 113: 885 (1974).

22. Leung, C. C. K., Watabe, H., and Brent, R. L.: The effect of heterologous antisera on embryonic development. XIII. Lack of effect of antisera to alpha fetoprotein. Am. J. Anat., 148: 457 (1977).

23. Miklailov, V. M.: Pathogenic action of nephrocytotoxic serum on embryonic development of albino rats. Biull, Eksp. Biol. Med., 63: 97 (1967).

24. New, D. A. and Brent, R. L.: Effect of yolk-sac antibody on rat embryos grown in culture. J. Embryol. Exp. Morphol., 27: 543 (1972).

25. Pierce, G. B., Jr., Beals, T. E., Ram, J. S., and Midgley, A. R., Jr.: Basement membranes. IV. Epithelial origin and immunological cross reactions. Am. J. Path., 45: 929 (1964)

26. Pierce, G. B., Midgley, A. R., Ram, J. S., and Feldman, J. D.: Parietal yolk sac carcinoma: Clue to the histogenesis of Reichert's membrane of the mouse embryo. Am. J. Pathol., 41: 549 (1962).

27. Pressman, D. and Korngold, L.: Localizing properties of anti-placenta serum. J. Immunol., 78: 75 (1957).

28. Slade, B. S. and Wild, A. E.: Transmission of human gamma-globulin to rabbit foetus and its inhibition by conjugation with ferritin. Immunology, 20: 217 (1971).

29. Slotnick, V. and Brent, R. L.: The production of congenital malformations using tissue and antisera. V. Fluorescent localization of teratogenic antisera in the maternal and fetal tissue of the rat. J. Immunol., 96: 606 (1966).

30. Unanue, E. R. and Dixon, F. K.: Experimental glomerulonephritis: immunological events and pathogenic mechanisms. In: Advances in Immunology (F. J. Dixon and J. H. Humphrey, eds.), Vol. 6. p. 1. (Academic Press, New York, 1967).

31. Vaillancourt, P. and McCallion, D. J.: Inhibitory effects of nephrotoxic antisera on the growth of rat fetuses. Am. J. Obstet. Gynecol., 114: 255 (1972).

32. Wilson, J. G.: Methods for administering agents and detecting malformations in experimental animals. In Teratology: Principles and Techniques. p. 251. (J. W. Wilson and J. Warkany, eds.) (Univer. of Chicago Press, Chicago, 1964).

33. The author thanks Dr. W. David Billington for providing the opportunity to initiate this work while he was visiting Dr. Billington in the University of Bristol, England. The author also thanks Ms. Mercedes Black for her excellent technical assistance, Mrs. Tuyetlan $\Upsilon$. Bui for taking the electron micrographs, and Mrs. Gloria Marshall for typing the manuscript. This work was supported by U.S. Public Health Service Research Grant HD 13939 and HD 13940 from the National Institute of Child Health and Human Development.

34. Requests for reprints should be addressed to: Dr. Christopher C. K. Leung, Department of Anatomy, Louisiana State University School of Medicine, Shreveport, LA 71130.

35. Received for publication June 1, 1982

36. Accepted for publication October 1, 1982. 